Discussion Paper No. 18-020

Go for Gigabit?

First Evidence on Economic Benefits of (Ultra-)Fast Broadband Technologies in Europe

Wolfgang Briglauer and Klaus Gugler

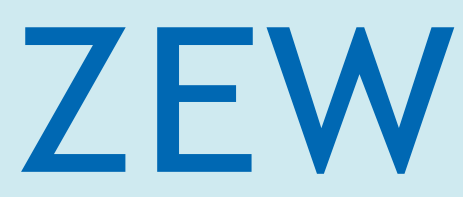

Zentrum für Europäische Wirtschaftsforschung $\mathrm{GmbH}$

Centre for European

Economic Research 
Discussion Paper No. 18-020

\section{Go for Gigabit? \\ First Evidence on Economic Benefits of (Ultra-)Fast Broadband Technologies in Europe}

Wolfgang Briglauer and Klaus Gugler

Download this ZEW Discussion Paper from our ftp server:

http://ftp.zew.de/pub/zew-docs/dp/dp18020.pdf

Die Discussion Papers dienen einer möglichst schnellen Verbreitung von neueren Forschungsarbeiten des ZEW. Die Beiträge liegen in alleiniger Verantwortung der Autoren und stellen nicht notwendigerweise die Meinung des ZEW dar.

Discussion Papers are intended to make results of ZEW research promptly available to other economists in order to encourage discussion and suggestions for revisions. The authors are solely responsible for the contents which do not necessarily represent the opinion of the ZEW. 


\title{
Go for Gigabit? First Evidence on Economic Benefits of (Ultra-)Fast Broadband Technologies in Europe
}

\author{
Wolfgang Briglauer*, Klaus Gugler**
}

April, 2018

*(Corresponding author) ZEW Centre for European Economic Research, MaCCI Mannheim Centre for Competition and Innovation, P.O. Box 1034 43, D-68034 Mannheim, Germany. Email: briglauer@zew.de.

** Vienna University of Economics and Business, Department of Economics and Research Institute for Regulatory Economics, Welthandelsplatz 1, 1020 Vienna, Austria, klaus.gugler@wu.ac.at.

Financial support by the State Government of Baden-Württemberg, Germany, through the research program 'Strengthening Efficiency and Competitiveness in the European Knowledge Economies' (SEEK) is gratefully acknowledged. 



\begin{abstract}
The literature on the effects of telecommunications infrastructure investments find positive macroeconomic effects, however, it is severely constrained because it could hitherto only analyze investment up to "basic" broadband but not up to the newer generations of "fast" and "ultra-fast" broadband; in particular there is no such evidence available at the EU level so far. Utilizing a comprehensive panel dataset of EU27 member states for the period from 2003-2015, we estimate a small but significant effect of fiber-based ultra-fast broadband over and above the effects of basic broadband on GDP. Adoption of hybrid-fiber fast broadband is incrementally to basic broadband insignificant. Our cost-benefit analysis implies that policy intervention - as foreseen by the European Commission in its public policy targets - is only justified for coverage and adoption levels of around 50\% of fast or ultra-fast broadband, whereas for $100 \%$ coverage levels we find net losses to society. Thus, it appears that - for the time being and according to the policy principle of "technological neutrality" - a combination of basic broadband, fast and ultra-fast broadband entails the largest economic net benefits to society.
\end{abstract}




\section{Introduction}

In the late 1990s broadband markets experienced their first disruptive innovation when internet technology was transformed from narrowband to "basic" broadband via DSL and cable modems based on copper-wire and coaxial-cable access infrastructures, respectively. On the grounds of alleged huge positive externalities, economists analyzed the effects of these telecommunications infrastructure investments on broader macroeconomic growth (e.g. Waverman and Roeller (2001) and Czernich et al. (2011), and broadly found a positive effect. Currently, electronic communications markets are again subject to major disruptive innovations when moving to either hybrid ("fast") or wholly ("ultra-fast") fiber-optical (wireline) infrastructure in the "last mile" of access networks or on the upcoming mobile (wireless) broadband generation technology (“5G”). These technologies offer various bandwidth levels from at least $30 \mathrm{Mbps}$ to several Gbps depending on the individual network technologies, and are said to be "future proof", because bandwidth is limited by the terminal equipment rather than the fibre infrastructure or the optical transmission technology. Deployment costs, however, also increase disproportionately when moving from fast to ultra-fast fiber technologies. Therefore, it is important to weigh economic benefits and economic costs, when deciding on the speed of broadband deployment and associated policies.

The deployment of fast and ultra-fast broadband technologies is of course a hot policy topic. Following the Digital Agenda Europe (DAE) objectives for 2020 (European Commission, 2010), the European Commission (EC) recently expressed ambitious and specific long-term objectives for 2025 which show a strong emphasize on the promotion of very-high capacity networks which enable gigabit-connectivity (European Commission, 2016a). ${ }^{1}$ Although the

\footnotetext{
${ }^{1}$ In its gigabit society agenda the EC defines three strategic objectives aiming at: "1. Gigabit connectivity for all main socio-economic drivers such as schools, transport hubs and main providers of public services as well as digitally intensive enterprises. 2. All urban areas and all major terrestrial transport paths to have uninterrupted 5G
} 
objectives therein appear to be defined technologically neutral, the EC implicitly favors highend ultra-fast network technologies (e.g. European Commission, 2016a, recital 13 and Art. 2 No. 1). This is the very first paper to analyze the effects of different forms of broadband technologies on macroeconomic growth, in particular providing much needed evidence on the effects of ultra-fast broadband at the EU level.

According to proponents of ultra-fast gigabit deployment strategies, capacity demand will be filled by consumers to enjoy better online entertainment services such as video streaming, business specific applications such as machine-to-machine or cloud computing services or in view of major industry developments such as autonomous driving or e-health. For such services only ultra-fast gigabit networks could ensure high enough and future proof levels alongside all relevant quality dimensions, such as high bandwidth, symmetry, reliability and security and low latency, jitter and packet loss. The notion of broadband internet as a general-purpose technology (Bresnahan and Trajtenberg, 1995) suggests that broadband deployment and adoption of services and applications lead to innovations and productivity increases in many major sectors of the economy which ultimately gives rise to growth in total factor productivity.

From a dynamic perspective the core question is to what extent welfare is lost by slower rather than faster migration to ultra-fast gigabit networks and whether dirigiste market interventions in terms of favoring certain broadband technologies in public policy targets instead of market driven technology choices ("technological neutrality") is justified in view of considerable higher deployment costs. The answer depends on the extent of "incremental" economic benefits related to ultra-fast broadband technologies and on the further evolution of technological progress of fast broadband. As will be shown in Section 2, the literature on economic effects

coverage. 3. All European households, rural or urban, to have access to Internet connectivity offering a downlink of at least 100 Mbps, upgradable to Gigabit speed" (European Commission, 2016b, 35-36). 
related to specific fiber technologies is extremely scant, and the evolution of future technology standards and demand is subject to high uncertainties. This implies that rigorous empirical evidence is much needed here; accordingly, we aim to answer the following research question: What are the incremental economic benefits of (ultra-)fast fiber technologies vis-à-vis basic broadband and do incremental benefits justify favoring high-cost investment scenarios?

We utilize a comprehensive and recent panel dataset on 27 EU member states from 2003 to 2015 covering almost the entire fiber-deployment period. The present analysis is the first that provides econometric evidence based on EU data with unique data for all relevant wireline ${ }^{2}$ broadband technologies. We employ a two-fold research strategy: First, in order to identify causal effects of individual broadband technologies on economic benefits, which we measure in terms of gross domestic product (GDP), we explicitly account for potential endogeneity utilizing panel econometric estimators with instrumental variables. Second, we relate estimated benefits of broadband adoption to available cost estimates of external industry studies in order to provide some rudimentary cost-benefit analysis. We find that the incremental benefits of (ultra-)fast broadband are statistically significant and larger than of fast broadband, however, we estimate the largest growth effects for basic broadband adoption. Our cost-benefit analysis reveals that partial but not full ultra-fast broadband coverage entails the largest net benefits.

The paper is organized as follows: Section 2 first reviews the recent and most related empirical literature. Section 3 then presents the empirical baseline specifications and our identification strategy. Section 4 describes our panel data set. Section 5 discusses the main results of our

\footnotetext{
${ }^{2}$ Although wireless (mobile) broadband will exert an increasingly important role in view of 4G and upcoming $5 \mathrm{G}$ technology standards (as also acknowledged in the EC's gigabit society agenda), the competitive impact on (ultra)fast wireline broadband has been limited in the past in view of still vastly lower average bandwidth levels.
} 
empirical estimation and cost-benefit analysis. Finally, Section 6 summarizes and compiles most relevant policy recommendations.

\section{Literature review}

Communications infrastructure deployment typically yields direct and indirect effects with respect to growth in a country's GDP (ITU/UNESCO, 2011). ${ }^{3}$ First, there is a direct effect upon output (and jobs) in the course of supplying new network infrastructure as additional employment and economic production is generated and due to related multiplier effects. Indirect economic benefits of broadband on the basis of deployed infrastructure are related to adoption of services or applications on the demand side. Adoption in firms gives rise to potential productivity gains via more efficient business processes, e.g. due to remote monitoring, logistics management and online procurement, or acceleration of innovation on new products and new business creation (ITU/UNESCO, 2011, pp. 33-34). Adoption by residential consumers drives real household income through various channels; for instance, consumers (and the public and other sectors) benefit from broadband adoption via easy and cheap access to e.g. administration or banking services. Broadband provides enhancements in education skills via distance learning and teaching subject to wide range of teaching materials available at every location. Likewise, education serves as an essential skill complementarity for entrepreneurial adoption to realize productivity gains (Akerman et al., 2015).

The study of the economic impacts of broadband internet has attracted a significant amount of empirical research. A recent survey by Bertschek et al. (2016) reviews more than 60 studies that investigate the causal effects of broadband availability and adoption on most relevant economic outcomes such as economic growth, employment as well as productivity and firm

\footnotetext{
${ }^{3}$ Greenstein and McDevitt (2011) show that additional broadband benefits for consumers exist which are not covered in standard GDP statistics.
} 
performance. Note that availability in terms of broadband coverage identifies investment activities, whereas adoption on the demand-side impacts on economic outcomes. The former are typically more informative from a policy perspective (e.g. the impact of regulation or public funding on investment incentives), whereas the latter are more informative from a welfare perspective or for a cost-benefit analysis.

Following the seminal contribution of Röller and Waverman (2001) - who investigate the impact of narrowband landline telecommunications infrastructure on economic growth in 21 OECD countries from 1970 to 1990 - several country-level studies investigate the impact of broadband infrastructure on economic growth. Koutroumpis (2009) examines the relationship between broadband adoption and GDP growth utilizing data for 22 OECD countries from 2002 to 2007. The author finds a significant positive impact of broadband adoption on GDP with a one percent increase in broadband adoption generating a 0.023 percent increase in GDP growth. Czernich et al. (2011) employ data for 25 OECD countries from 1996 to 2007 and find that a 10 percentage point increase in the rate of broadband adoption led to a 0.9 to 1.5 percentage point increase in annual growth of GDP per capita. Gruber et al. (2014) use data for EU27 states from 2005 to 2011 to evaluate the benefits and costs of the DAE. Their estimates suggest that broadband adoption rates had a significant and positive effect on GDP in the observed period.

Only very few unpublished studies or policy reports explicitly include (ultra-)fast fiber-based broadband data. Sosa (2015) estimates the differential effect of gigabit broadband availability which is measured at the U.S. state level for nine states where at least $50 \%$ of households have gigabit coverage. Data is available for the years 2011 and 2012. The authors control for the unemployment rate, state and period fixed effects and find that per capita GDP is about 1.1 percent higher than in states that have less than 50\% gigabit coverage. Bai (2016) is another recent study that examines the impact of different broadband speed levels using U.S. county level data for the years from 2011-2014. The study is closest to our approach as it employs data 
on speed levels which proxy quite well different basic broadband, fast-fiber and ultra-fast fiber technologies. The author assesses the differential impact on employment and finds a positive impact of broadband availability, but, compared to basic broadband, (ultra-) fast broadband did not generate substantially greater positive effects on employment. Fabling and Grimes (2016) estimate the productivity gains from ultra-fast broadband adoption on employment using firmlevel fiber data for New Zealand for the years 2010 and 2012. The authors find no significant effect of ultra-fast broadband on employment on average, but only for firms making complementary investment in organizational capital.

Summarizing, the general result of a positive and statistically significant effect of basic broadband availability (or adoption) on either GDP or GDP growth is found at the macro-level in all reviewed country-level studies (Bertschek et al., 2016). However, there is still only very scant empirical evidence available so far as regards the differential impact of various (ultra)fast broadband technologies on economic outcomes such as employment and economic growth. The existing studies are unpublished and non-EU based (New Zealand and the U.S.) and there is no evidence available so far that allows drawing conclusions on the desirability of the policy targets defined at member state and EU level favoring the promotion of gigabit networks based on ultra-fast fiber technologies. The aim of our work is to fill this research gap and to truly inform the policy debate ongoing at the EU level and in other jurisdictions.

\section{Empirical specification}

In what follows, we first outline our empirical baseline specification in Section 3.1, while we describe our identification strategy in Section 3.2.

\subsection{An Augmented Production Function}

Following the specifications in Röller and Waverman (2001), Koutroumpis (2009) and Czernich et al. (2011), national aggregate economic output $(G D P)$ is related to various input factors, i.e., labor $(L)$ and all forms of non-broadband capital stock $(C)$. The starting point of 
analysis is a production function which allows for different levels of technology $(A)$ in country $i$ in period $t$ and reads as follows:

$$
G D P_{i t}=A_{i t} F\left(L_{i t} ; C_{i t}\right)
$$

$A_{i t}$ represents total factor productivity given the levels of capital and labor and is considered here as part of the growth that cannot be attributed to changes in observable production inputs but to a number of unobservables affecting overall efficiency. In Equation (1) it is assumed that the production function has the same functional form in each country and is separable in $A_{i t}$. As another starting point most empirical estimations assume a Cobb-Douglas type production function (Cardona et al., 2013) where all input factors are weighted by their (constant but otherwise unconstrained $)^{4}$ output elasticities. Rewriting Equation (1) thus yields:

$$
G D P_{i t}=A_{i t} L_{i t}^{\alpha_{L}} C_{i t}^{\alpha_{C}} \quad \text { Equation (2) }
$$

where $\alpha_{L}$ and $\alpha_{C}$ represent the output elasticities of labor and capital, respectively. Following Czernich et al. (2011) we further assume that the technological state evolves according to an exponential growth pattern:

$$
A_{i t}=A_{0} e^{\lambda_{i t}}
$$

where $\lambda_{i t}$ is the growth parameter of technological progress in country $i$ and period $t$. The notion of broadband internet as a general-purpose technology suggests that it will also impact the growth parameter $\lambda_{i t}$ by continuously spurring innovation and the adoption of new broadband services in many sectors of the economy. We thus assume the following functional relationship:

$$
\lambda_{i t}=\alpha+\beta^{u f} \ln \left(B B_{i t}\right)+\beta^{f a} \ln \left(B B_{i t}^{f a}\right)+\beta^{b a} \ln \left(B B_{i t}^{b a}\right) \quad \text { Equation (4) }
$$

\footnotetext{
${ }^{4}$ In particular, we do not impose any assumptions on returns to scale.
} 
where the parameters $\beta^{u f}, \beta^{f a}$ and $\beta^{b a}$ represent the output elasticities related to different broadband technologies (ultra-fast $(u f)$; fast $(f a)$, basic $(b a)$ ). $B B_{i t}$ 's measure real broadband connections in terms of deployed and fully adopted connection lines, since the main impact on economic growth is associated with the adoption (and not the mere deployment) of broadband connections accruing from usage of new services and applications (see discussion below).

Taking logs of the production function in Equation (1), substituting for $\lambda_{i t}$ and adding a vector of covariates $\boldsymbol{X}_{i t}$ to capture time-variant heterogeneity within countries, country fixed effects $\left(\alpha_{i}\right)$ and period effects $\left(\alpha_{t}\right)$ as well as an error term $\varepsilon_{i t}$ yields the following estimating equation:

$$
\begin{aligned}
\ln \left(G D P_{i t}\right)= & \alpha+\alpha_{L} \ln \left(L_{i t}\right)+\alpha_{C} \ln \left(C_{i t}\right) \\
& +\beta^{u f} \ln \left(B B_{i t}^{u f}\right)+\beta^{f a} \ln \left(B B_{i t}^{f a}\right)+\beta^{b a} \ln \left(B B_{i t}^{b a}\right) \\
& +\gamma \mathbf{X}_{i t}+\alpha_{i}+\alpha_{t}+\varepsilon_{i t}
\end{aligned}
$$

From the previous discussion we expect all $\beta^{\prime} s>0$. Furthermore, if the EC's presumptions expressed in its gigabit targets are correct, we should also observe $\beta^{u f}>\beta^{f a}$, i.e. a larger incremental effect of ultra-fast than of fast broadband. As regards period and country fixed effects it is assumed that they do not interact with any of the inputs factors. The vector of covariates $\boldsymbol{X}_{i t}$ includes macroeconomic control variables. Period effects capture macroeconomic shocks which are common to all countries and are not captured in $\boldsymbol{X}_{i t}$.

In case of basic broadband as analyzed in the older empirical literature, the distinction between availability and adoption was less relevant in view of typically rather high take-up rates (i.e. the ratio between adopted connections to all available connections). ${ }^{5}$ In contrast, this distinction is

\footnotetext{
${ }^{5}$ For instance, Czernich et al. (2011) employ a measure which defines a broadband line as a connection that enables download speed >= $256 \mathrm{kbit} / \mathrm{s}$. As their data includes almost entirely basic broadband lines (including only a small amount of fiber-based lines at the very end of their period of analysis (1996-2007)), the underlying take-up rates were rather high.
} 
of high relevance in (ultra-)fast broadband markets, where take-up rates are persistently low in most European countries (i.e. far below $30 \%$ on average, see Figure 2(a) in Section 4.1). Low take-up rates imply that willingness of consumers to adopt and therefore migrate to the new broadband services is moderate on the demand side which also gives rise to substantial and costly over-capacities on the supply-side. Accordingly, the empirical studies employing measures of broadband investment (availability) only estimate a reduced form where the estimated coefficients represent a proportional effect on economic outcomes which is smaller than the effect via broadband adoption (Czernich, 2014). Whereas the former measures the intention-to-treat effect, the latter primarily impacts economic outcomes and is a function of broadband availability. In that sense, impact assessments of the underlying infrastructure availability underestimate economic effects and realized welfare gains. Only in case of full network utilization (i.e. take-up rate is equal to one), the intention to treat effect is the same as the treatment effect. In view of low (ultra-)fast broadband take-up rates, we thus employ data on output-related broadband adoption $\left(B B_{i t}{ }^{\prime} s\right)$ to estimate the augmented production function in Equation (5). ${ }^{6}$

\subsection{Identification strategy}

Estimating Equation (5) has to take into account potential endogeneity, in particular, GDP and broadband adoption might be simultaneously determined, as the introduction of broadband technologies and its subsequent adoption might depend on the economic development in a certain country. Communications expenditure represents a non-negligible part of consumers' income in developed countries which thus exerts an impact on adoption of broadband. In particular, ultra-fast broadband services represent a premium service for most consumers and hence its demand will depend on consumer income and wealth. Another source of endogeneity is related to omitted variables such as broadband subsidies (Czernich et al., 2011). This form of

\footnotetext{
${ }^{6}$ For the sake of clarity, we drop the sub-indices in the remainder of the paper.
} 
intervention is strongly promoted at EU and member state levels in order to realize expected social benefits of broadband coverage and adoption and to avoid "digital divide" in rural areas. Rural areas are unprofitable for private operators and hence require public funds to achieve desired target levels. However, the profitability gap is inter alia determined by the economic development and the wealth of consumers in a specific country. Finally, politicians might consider broadband subsidies as a reasonable form of intervention to re-boost the economy during an economic downturn.

In view of the above sources of endogeneity, we employ a two-stage-least squares (2SLS) estimator using two sets of sources of exogenous variation:

First, regulation of broadband infrastructure and competition in broadband markets will have a strong impact on both, investment and adoption. Regulation in general exerts a twofold impact which is well documented in the theoretical and empirical literature: on the one hand, it impacts on investment and innovation incentives of regulated and unregulated operators. On the other hand, it is supposed to stimulate (service-based) competition by enabling alternative operators to access monopolistic bottlenecks (broadband infrastructure) at regulated charges. ${ }^{7}$ The former effect impacts adoption via investment activities, whereas the latter impacts adoption as it pushes retail competition and yields lower prices. Similarly, competition in broadband markets stemming from independent mobile and all other (non-incumbent) wireline network operators determines retail prices and quality levels and hence adoption in broadband markets. The related

\footnotetext{
${ }^{7}$ Note that traditional access regulations imposed on basic and new broadband infrastructure, only require the dominant ("incumbent") operators to provide forms of access to their network infrastructure. The term incumbent refers to former - mostly state-owned - telecommunications monopolists of wireline networks.
} 
empirical literature indeed identified regulation and relevant modes of competition as key determinants of broadband investment and adoption. ${ }^{8}$

Second, broadband adoption in other (non-focal) EU member states may exert considerable pressure on national politicians not to fall too far behind the development in other member states. In fact, in its gigabit strategy the EC explicitly acknowledges as a great success of the former broadband policy target as expressed in its DAE: “[t]hese objectives progressively have become a reference for public policy. ... At national level, setting objectives has become the cornerstone of broadband deployment public policy. ... Many member states have indeed aligned their national or regional NGN [=next generation networks] plans to the DAE speeds" (European Commission, 2016b, p. 31). We thus expect that national broadband adoption is strongly influenced by average adoption of basic and (ultra-)fast broadband in all other (nonfocal) EU member states which at the same time should not have any direct impact on national GDP.

We estimate the baseline specification in Equation (5) utilizing an ordinary fixed effects (FE) estimator as well as a 2SLS FE estimator with an overidentifying set of external restrictions which allows us to examine the validity of our instruments and causality of our main variables of interest. Furthermore, in estimating Equation (5) we include several macroeconomic controls as well as member state and year fixed effects.

\section{Data}

We employ an unbalanced panel data set of EU27 member states for the period from 2003-2015 for dependent and independent variables. In constructing our data we use three main sources:

\footnotetext{
${ }^{8}$ For the older basic broadband related literature the reader is referred to e.g. Koutroumpis (2009), Boukaert et al. (2010), Grajek and Röller (2012) and Nardotto et al. (2015); for the newer and (ultra-)fast broadband related literature the reader is referred to Bacache et al. (2014) and Briglauer (2014; 2015).
} 
First, for our dependent variable measuring real gross domestic product $(G D P)$ at constant 2011 prices as well as for variables measuring non-broadband real capital stock (capital_stock) and labour in terms of total hours worked (work_hours) we utilize data from the Penn World Table. Second, our source for the main independent variables of interest is the database of FTTH Council Europe, which includes annual numbers of adopted (ultra-)fast broadband lines for EU member states (Section 4.1). In view of the baseline specification in Equation (5) we take logs of GDP, capital and labour inputs and all broadband variables. ${ }^{9}$ Third, we use data from the EC's "Progress Report on the Single European Electronic Communications Market" in conjunction with its "Digital Agenda Scoreboard" which provide data on basic broadband and related access regulations as well as data on competition in broadband markets. Finally, we also employ several other data sets to construct our control variables (Section 4.2) and instrumental variables (Section 4.3).

All sources and variable definitions are listed and described in detail in Table A.1, while descriptive statistics are provided in Table A.2 in the Appendix. Owing to the fact that some values are missing, ${ }^{10}$ there are fewer observations than the maximum number $(13 * 27=351)$ and some $0.74 \%$ of all the raw data were calculated using linear interpolation.

\footnotetext{
${ }^{9}$ A log transformation also helps to stabilize the series of our dependent and broadband related variables. In order to formally test for stationarity, we performed "Im-Pesaran-Shin" and "Fisher-type" unit-roots tests. These tests are designed for unbalanced panels and reject the null hypothesis that all panels contain unit roots for the abovementioned variables in logs.

${ }^{10} \mathrm{EU}$ data related to access regulations imposed on broadband markets and basic broadband adoption are missing for Eastern European countries in the early phase of our period of analysis (years from 2003 to 2006). Some of the Eastern European countries entered the EU at later stages and thus were not subject to the EU regulatory framework and obliged to report data before. Obviously, these missing values are related to political decisions but not to broadband deployment or GDP growth. Furthermore, FTTH Council Europe data are missing for the initial period
} 


\subsection{Broadband variables}

Our main variables of interest represent different broadband adoption technologies denoted with $B B$, which measure real numbers of subscribing consumers and business who show sufficient willingness to pay for broadband services. These variables differ from broadband availability measured in real terms as physical connections deployed (installed capacity).

Depending on the fibre reach different broadband technologies are distinguished: (ultra-)fast broadband is denoted with $B B^{u f}$ and is defined as the sum of high-end "Fiber-to-the-home" (FTTH) and "Fiber-to-the-building" (FTTB) network scenarios. Fast broadband, denoted with $B B^{f a}$, comprises hybrid-fiber network scenarios based on so-called "VDSL/vectoring" technologies employed by former monopolist (incumbent) operators. This case is referred to as "Fibre to the cabinet" (FTTC). The other hybrid case is based on coaxial-cable technologies of cable-TV operators. This case is also referred to as "Fibre-to-the-last-amplifier" (FTTLA). Both hybrid broadband networks rely on old copper-wire and coaxial-cable lines in the remaining part of the access network connecting the customer premise with the last distribution point. From that point on all data transmission is fiber-based. In contrast, basic broadband technologies, $B B^{b a}$, mainly rely on old copper- or coaxial cable and DSL or cable modem technologies in the entire network. Note, however, that our measure for basic broadband adoption, i.e. connections with download speed $>=256 \mathrm{kbps}$, by this definition also includes fast and ultra-fast broadband connections although the vast majority of basic broadband connections consists of much lower bandwidth levels.

Figure 1 shows average EU deployment patterns as regards availability (i.e., real investment) and adoption (i.e., actual usage) of (ultra-)fast broadband for the years from 2005-2015. In view of the total number of households in EU27 (about 218.072.600 in 2015), this results in an

of (ultra-)fast broadband adoption in some EU member states. In cases of missing or zero values of the (ultra-)fast broadband variables the logarithm does not exist and hence we replaced these observations with zero values. 
average household coverage with (ultra-)fast broadband (246.193.367 households in 2015) of about $113 \% .{ }^{11}$ This number is above $100 \%$ due to a parallel coverage with (ultra-)fast broadband infrastructure, in particular in urban areas, where homes and business are often supplied by incumbent, cable and other wireline operators. However, the natural saturation level for (ultra-)fast adoption is $100 \%$, as households and business normally will not subscribe to multiple connections, considering the huge bandwidth capacity of a single fiber-based connection.

In order to capture this asymmetry in maximum adoption and coverage levels, an alternative measure is the take-up rate (TUR). As one can infer from Figure 1, the gap between available and adopted (ultra-)fast broadband connections, has widened considerably which led to low take-up rates for both technologies (Figure 2 (a)). Note that this phenomenon is more pronounced with respect to fast broadband. As of 2015 for instance, take-up rates of fast and ultra-fast broadband were about 20.6\% ((38.51/187.03)*100) and 25.9\% ((15.33/59.16)*100), respectively (Figure 1 and Figure 2 (a)).

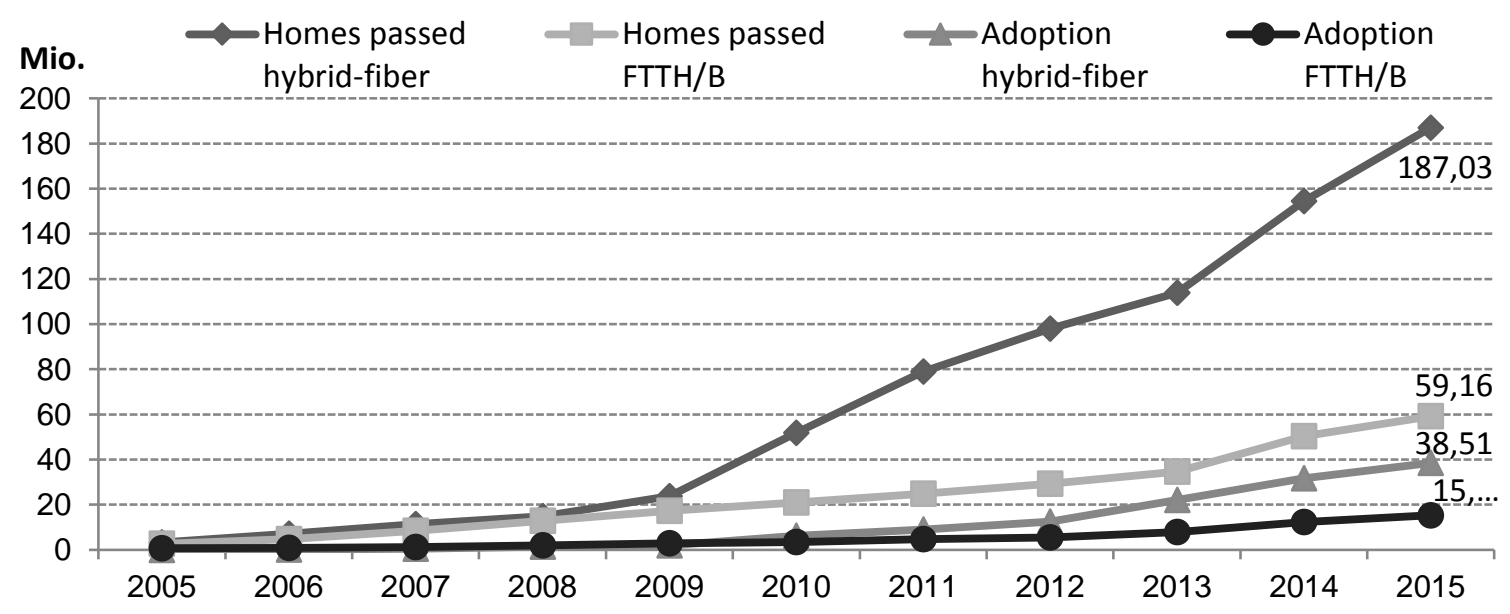

Figure 1: Availability and adoption of (ultra-)fast broadband in EU27 (Mio. of households)

\footnotetext{
${ }^{11}$ Source for household data: Euromonitor.
} 
Basic broadband adoption, $B B^{b a}$, has been available on average to almost $98 \%$ of EU households during our period of analysis (European Commission, 2016c). As we do not have panel data on basic broadband availability, we report adoption rates instead of take-up rates in Figure 2 (b). Although almost $30 \%$ of EU households still do not have a subscription as of 2015 (Figure 2 (b)), basic broadband take-up rates are much larger than for fast and ultra-fast broadband. It appears therefore that it is important that most households are supplied by basic broadband, but fast and ultra-fast broadband only for an - albeit increasing - share of households. Fast and ultra-fast broadband is either (still) too expensive and/or the benefits are (still) too small to be adopted at a larger scale.
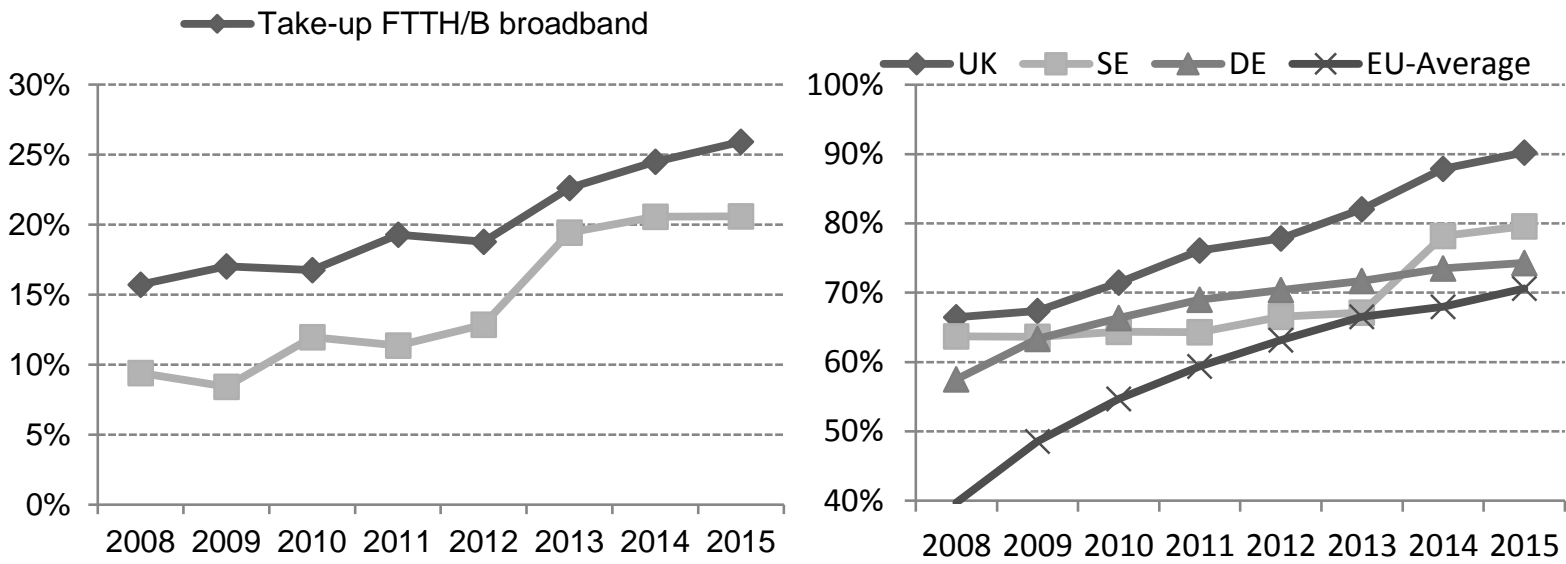

Figure 2: (a) and (b)

(a) Average EU27 take-up rates (=adopted connections/available connections) of (ultra-) fast broadband in \% (b) Adoption rate (= adopted connections per households) of basic broadband in \% in EU27 and selected member states

\subsection{Control variables}

We employ the following macroeconomic controls in estimating the aggregate production function in Equation (5): The long-term interest rate (interest rate) as well as indices measuring the degree of economic freedom (eco_freedom) and a country's networked readiness ( $n r i)$ in terms of its propensity to exploit the opportunities offered by information and communications technology (ICT). We expect that a higher degree of economic freedom and network readiness 
translates into higher GDP. The long-term interest rate for debt security issued at 10 years maturity captures financing costs and thus is expected to be negatively related to GDP.

\subsection{Instrumental variables}

As motivated in Section 3.2, we employ two distinct sources of exogenous variation to identify causal effects of broadband on GDP: i) access regulations and competition in broadband markets, and ii) broadband adoption in all other (non-focal) EU member states. We argue that these variables affect adoption of broadband but not GDP growth.

i) Broadband access regulation is measured by the monthly so-called unbundling access price, denoted $l l u \_p r i c e$, which has been by far the most important broadband access remedy under the EU regulatory framework since the beginning of telecommunications markets liberalization (European Commission, 2016d). A larger access price implies more lenient regulation of the incumbent and less scope for service-based competition. Infrastructure-based competition in broadband markets is measured by relevant forms of competition stemming from mobile (mobile_comp) and all other (non-incumbent) wireline broadband networks (broadband_comp). Mobile and wireline broadband services provided over independent networks (and via unbundling regulations) exert substantial competitive pressure on the former incumbent monopolist operator. We expect regulation and competition in broadband markets to significantly affect price and quality of fiber-based services and thus adoption, but not GDP directly.

ii) Average broadband adoption in all other (non-focal) EU member states is denoted with $B B^{f a}$ eu26, $B B^{u f}$ eu26, $B B^{b a}$ eu26. It is defined as the ratio of household broadband adoption with fast, ultra-fast and basic broadband in EU26 countries (i.e. all other than the focal country) to the total number of other countries (27-1). Due to benchmarking effects, we expect below average countries to catch up. 


\section{Empirical results}

We first report estimation results on our aggregate production function (Equation (5)) in Section 5.1. Based on these results Section 5.2 provides a rudimentary cost-benefit analysis as regards the economic net benefits of relevant broadband access technologies. ${ }^{12}$

\subsection{Aggregate production function}

Table 1 and Table 2 show the main regression results for OLS and 2SLS fixed-effects (FE) specifications, respectively. Overall, OLS and 2SLS regression results largely point to a similar structure of coefficient estimates.

Table 1 first shows the main regression results for alternative OLS specifications. $F$-tests and $R^{2}$ (within) reported at the bottom of Table 1 indicate good explanatory power of the models. $F$-tests of the null hypothesis that all FE are zero clearly suggest that pooled OLS estimates would yield inconsistent estimates. We further examine whether errors are identically and independently distributed: ${ }^{13}$ A modified Wald test for groupwise heteroscedasticity rejects the null hypothesis of constant variance in all specifications. Likewise, a Wooldridge test for autocorrelation in panel data rejects the null-hypothesis of no first-order serial correlation in FE models. Accordingly, we impose standard errors which allow for arbitrary forms of heteroscedasticity and autocorrelation in all regressions.

To begin with, regression (1) only includes the basic broadband adoption variable $\left(\ln \left(B B^{b a}\right)\right)$, and finds a positive and significant effect on GDP. Accordingly, a $1 \%$ increase in basic broadband adoption increases GDP by about $0.015 \%$. Controlling for basic broadband adoption we find weak and marginally significant "incremental" effects for fast and ultra-fast broadband $\left(\ln \left(B B^{u f} ; \ln \left(B B^{f a}\right)\right)\right.$, in regressions (2) and (3), respectively (about $\left.0.002 \%\right)$. When dropping the

\footnotetext{
${ }^{12}$ Stata 13.1 is used to estimate the regressions.

${ }^{13}$ Regression specific test statistics are not reported but available upon request from the authors.
} 
basic broadband variable, we find a slightly higher and significant "baseline" effect (about $0.003 \%$ ) for fast and ultra-fast broadband in regressions (4) and (5), respectively. When controlling for all broadband technologies (regression (6)), coefficient estimates become insignificant due to collinearity problems; the latter is to be expected as basic broadband is measured cumulatively including all broadband connections with bandwidth levels $>=256$ kbps. Whereas the coefficient estimate for basic broadband is at the lower range of estimates identified in the related empirical literature (see Koutroumpis, 2009, and Czernich et al., 2011, for basic broadband adoption in OECD countries), the incremental effect of ultra-fast appears to be weak but significant (no comparable values from the previous literature available).

Coefficient estimates for the other (non-broadband) input factors labour and capital (ln(work_hours $) ; \ln ($ capital_stock $))$, are significant and exhibit a rather strong impact on GDP as expected. Our macroeconomic control variables (eco_freedom; nri; interest rate) are significant in most specifications and also show expected signs throughout.

Table 2 reports 2 SLS estimates which take into consideration potential endogeneity underlying our broadband adoption variables. To deal with endogeneity, we employ the regulation, competition and geography-based instruments described in Section 4.3 as sources of exogenous variation. According to Hansen tests our instruments are jointly valid in all specifications. First stage Angrist-Pischke (AP) $F$-statistics of excluded instruments suggest that our instruments are strong (close to or above the value of 10) for our broadband adoption variables. The Kleibergen-Paap (KP) test of underidentification clearly rejects the null hypothesis that that the respective estimating equation is underidentified for all regressions at the $5 \%$ significance level, implying that the excluded instruments are correlated with the endogenous regressors and thus relevant. $^{14}$

\footnotetext{
${ }^{14}$ First-stage results are available upon request from the authors.
} 
Durbin-Wu-Hausman (DWH) tests do not reject the null hypothesis of broadband adoption being an exogenous variable in all regressions. Hence, DWH tests suggest that included broadband variables can be considered as exogenous and OLS estimates reported in Table 1 are consistent and overall more efficient in this case. Nevertheless, 2SLS coefficient estimates suggest a larger influence of broadband adoption on GDP particularly for basic (albeit insignificant in regression (3)) and ultra-fast broadband. The estimates suggest that a $1 \%$ increase in adoption leads to an incremental increase of about $0.004-0.005 \%$ of GDP with respect to ultra-fast broadband and to a $0.002-0.003 \%$ increase with respect to fast broadband. The basic broadband coefficient estimate is 0.024 (insignificant). Estimated coefficient estimates of broadband adoption therefore suggest that the incremental benefits related to (ultra)fast broadband are positive and significant, while smaller for fast broadband.

All other coefficient estimates of non-broadband input and control variables are - if significant - in line with prior expectations and corresponding OLS estimates in Table 1. 
Table 1: OLS estimation results for production function model (Equation (5))

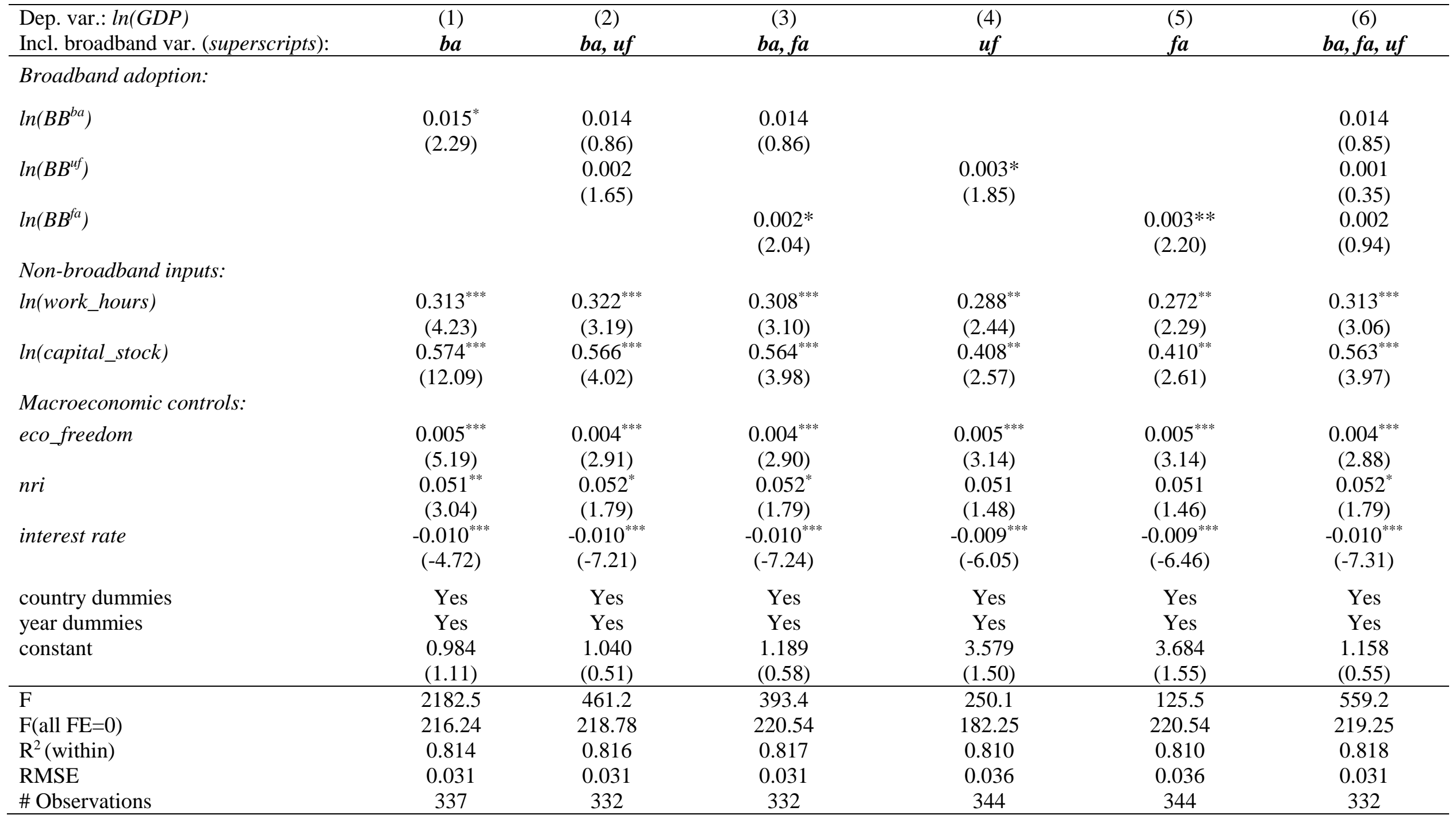

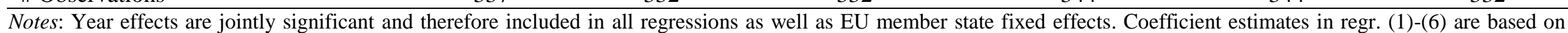
standard errors which allow for arbitrary forms of heteroscedasticity and autocorrelation. $t$-statistics in parentheses. ${ }^{*} p<0.10,{ }^{* *} p<0.05,{ }^{* * *} p<0.01$ 
Table 2: 2SLS estimation results for production function model (Equation (5))

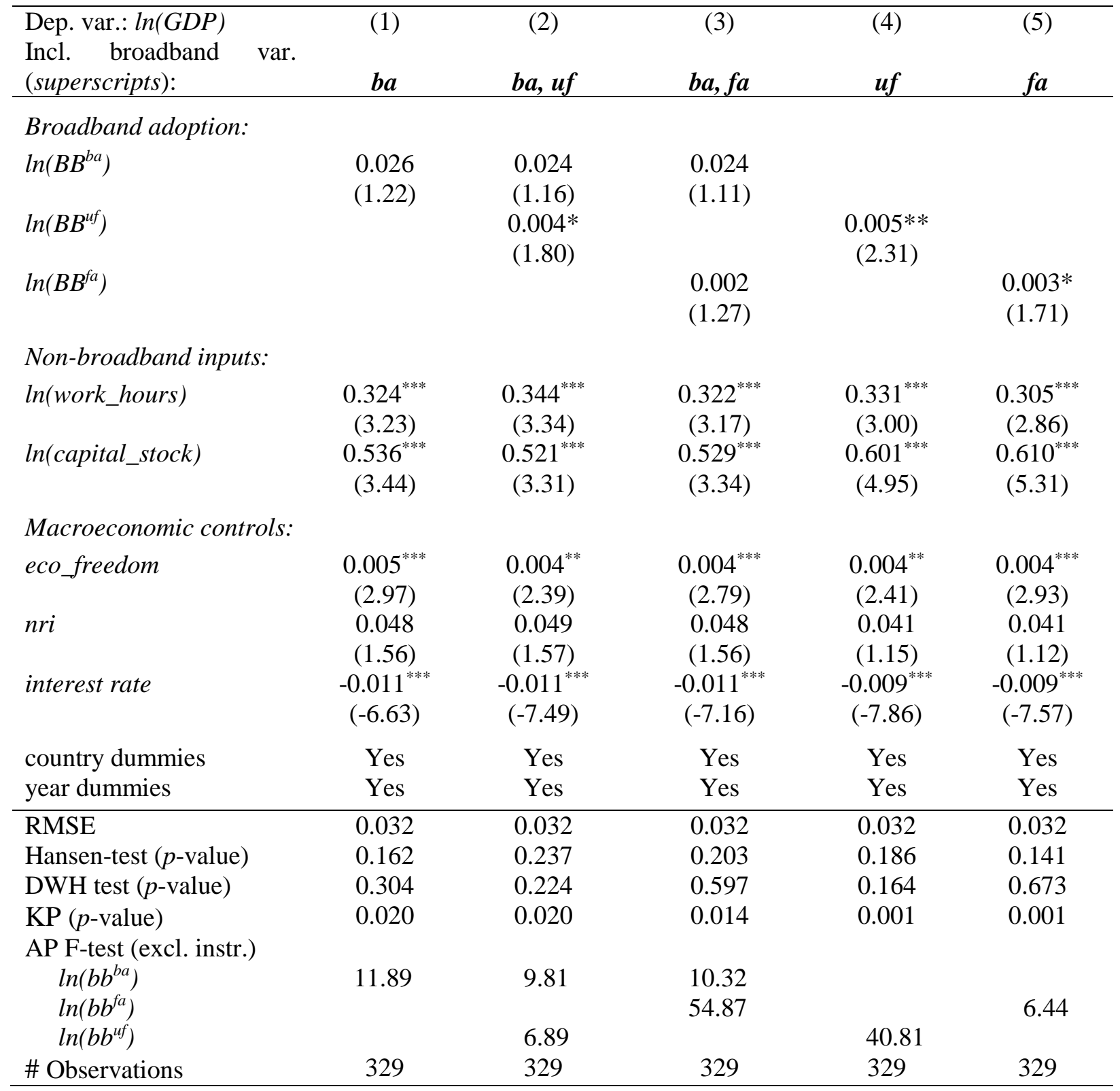

Notes: Year effects are jointly significant and therefore included in all regressions as well as EU member state fixed effects. We instrumented the broadband adoption variables $\ln \left(B B^{b a}\right), \ln \left(B B^{u f}\right)$ and $\ln \left(B B^{f a}\right)$ using the following list of excluded instruments: mobile_comp, broadband_comp and llu_price in regressions (1) to (5), $\ln \left(B B^{b a} \_e u 26\right)$ in regressions (1) to (3), $\ln \left(B B^{f a} \_e u 26\right)$ in regressions (3) and (5) and $\ln \left(B B^{u f} \_e u 26\right)$ in regressions (2) and (4). Coefficient estimates in all regressions are based on standard errors which allow for arbitrary forms of heteroscedasticity and autocorrelation. $t$-statistics in parentheses ${ }^{*} p<0.10,{ }^{* *} p<0.05,{ }^{* * *} p<0.01$ 


\subsection{Cost-benefit analysis}

Using our main estimation results, we aim to construct a basic cost-benefit analysis taking into account an array of estimated coefficients and different broadband technologies and targets. Table 3 below summarizes estimated benefits of broadband adoption and deployment derived from our empirical analysis in column 1. In our baseline scenario estimated EU average benefits are based on the upper bounds of the respective OLS and 2SLS coefficient estimates $(\bar{\beta})$ in Table 1 and Table 2 and we assume the highest value of fast and ultra-fast take-up rates (TUR ${ }^{2015}$ ) observed at the end of our period of analysis (i.e, $\sim 20 \%$ and $\sim 25 \%$ according to Figure 2 (a)). We thus focus on the best case scenario for policies favoring (ultra-)fast broadband targets. In order to establish a break even scenario, we calculate the required takeup rates $\left(\mathrm{TUR}^{\mathrm{r}}\right)$ at the lower and upper bounds of coefficient estimates $(\bar{\beta} ; \underline{\beta})$ which equalize costs. In case the external cost studies (column 2) provide interval estimates, we refer to the average of these cost estimates. Our assessment of average benefits is based on the grand mean of GDP $\left(G D P_{g m}\right)$ which is equal to 612346.5 million US\$ at constant 2011 national prices (Table A.1 and Table A.2) and corresponds to an amount of about 465376.72 million $€$ on the basis of average 2011 exchange rates. Finally, we assume that adoption grows linearly with coverage over the projected deployment period foreseen in the external cost studies until the targeted coverage level is reached. Given these assumptions, estimates of average benefits in (EUR bn) are calculated as follows: $\% \Delta G a p * T U R^{2015} * \bar{\beta}{ }^{*} G D P_{g m}$, where $\% \Delta G a p$ is the gap between broadband coverage at the beginning of the deployment period and the target year in percentage terms.

We contrast our estimates with the most comprehensive and recent industry cost studies on various broadband deployment scenarios (column 2). Column 2 also reports the gap in percentage terms, $\% \Delta G a p$, to the respective target underlying the cost estimations. Column 3 reports the source of the external cost studies. Although the selected cost studies make different 
assumptions which in parts deviate considerably from each other, they have similar dates of origin in each of the three target subheadings and therefore comparable forecasting periods. Gruber et al. (2014) - reviewed in Section 2 - is the only study that also provides a cost-benefit analysis with respect to the DAE targets. We include the authors' estimates for their deployment scenario - which relates infrastructure costs to FTTH technology - in target (ii).

From our cost-benefit analysis, the following results emerge:

First, at current take-up rates (TUR ${ }^{2015}$ ) benefits related to fast broadband services (target (i)) apparently do not cover estimated costs to close the coverage gaps as of 2011. This follows from our estimates based on the upper bound of coefficient estimates and two external cost studies referring to a deployment period from 2011 to 2020. At the beginning of this period the gap to the desired DAE coverage target (i) requiring $100 \%$ with at least $30 \mathrm{Mbit} / \mathrm{s}$ was about $104.08 \%$. Accordingly, an increase in coverage by this amount would yield an increase in adoption of about $20.82 \%$ assuming a $20 \%$ TUR. Multiplying this increase in fast broadband adoption with our upper bound coefficient estimate $\left(\bar{\beta}^{f a}=0.003\right)$ and the grand mean of GDP (=465376.72 million $€$ ) yields an estimated EU average benefit of about EUR bn 29.06 which is apparently below the respective cost estimates of both cost studies conducted by EIB (2011) and Analysis Mason (2013). Estimated break even TUR R's appear to be quite high (about 57\%, $64 \%$ and $38 \%, 43 \%$ for upper and lower bounds of coefficient estimates, respectively) in view of current take-up rates (about 20\%).

Second, ultra-fast broadband adoption (DAE target (ii)) comes along with higher estimated economic benefits that clearly (estimates in bold) or almost outweigh estimated deployment costs as reported in four different cost studies, including the only external cost-benefit analysis by Gruber et al. (2014). Also, required take-up rates are much lower for ultra-fast broadband. In contrast, benefits are apparently much lower compared to the much higher deployment costs 
related to the $100 \%$ coverage goal of the gigabit society agenda (target (iii)). Conversely, estimated $\mathrm{TUR}^{\mathrm{R} \prime}$ s are at higher levels.

To summarize, it appears that only the ultra-fast adoption target (ii) requiring a moderate coverage of (at least) 50\% shows an economic justification in view of total deployment costs. In case of universal (100\%) coverage with fast (target (i)) and ultra-fast broadband (target (iii)) estimated benefits are below all cost estimates in our baseline case and would require rather high take-up rates; again, at least for the time being the latter appear to be unrealistic especially for fast broadband service adoption. It appears therefore that a combination of basic and ultrafast or a combination of all three types of broadband access technologies entail the largest economic net benefits. 
Table 3: Benefits and costs of broadband adoption and coverage (EU27 averages)

\begin{tabular}{llc}
\hline Estimated benefits (EUR bn) & Estimated costs (EUR bn) & Source \\
\hline
\end{tabular}

(i) Fast broadband DAE coverage target

(30 Mbit/s with 100\% coverage with FTTH/B/C/FTTLA in 2020)

\begin{tabular}{llc}
\hline Total benefits: 29.062 & Total coverage cost: 55 & EIB \\
$\left(\bar{\beta}^{f a}: 0.003 ; \operatorname{TUR}^{2015}: 20 \%\right)$ & $\begin{array}{l}\text { Period: } 2011-2020 \\
\% \Delta \mathrm{Gap}^{(a)} \text { to target }(100 \%) \text { in 2011: 104.08\% }\end{array}$ & $(2011)$ \\
$\mathrm{TUR}^{\mathrm{r}}: \underline{\beta}^{f a}: \sim 57 \%\left(\bar{\beta}^{f a}: \sim 38 \%\right)$ & & \\
& & \\
Total benefits: 29.062 & Total coverage cost: 31-62 & Analysis \\
$\left(\bar{\beta}^{f a}: 0.003 ; \mathrm{TUR}^{2015}: 20 \%\right)$ & Period: 2011-2020 & Mason \\
$\mathrm{TUR}^{\mathrm{r}}: \underline{\beta}^{f a}: \sim 64 \%\left(\bar{\beta}^{f a}: \sim 43 \%\right)$ & $\% \Delta$ Gap to target $(100 \%)$ in 2011: 104.08\% & (2013) \\
\hline
\end{tabular}

(ii) Ultra-fast broadband DAE adoption target

(100 Mbit/s with 50\% adoption with FTTH/B in 2020) ${ }^{\text {(b) }}$

Total benefits: $\mathbf{2 2 1 . 5 0 1}$

$\left(\bar{\beta}^{u f}: 0.005 ; \mathrm{TUR}^{2015}: 25 \%\right)$

$\mathrm{TUR}^{\mathrm{r}}: \underline{\beta}^{u f}: \sim 39 \%\left(\bar{\beta}^{u f}: \sim 24 \%\right)$

Total benefits: 201.525

$\left(\bar{\beta}^{u f}: 0.005 ; \mathrm{TUR}^{2015}: 25 \%\right)$

$\mathrm{TUR}^{\mathrm{r}}: \underline{\beta}^{u f}: \sim 41 \%\left(\bar{\beta}^{u f}: \sim 23 \%\right)$

Total benefits: 201.525

$\left(\bar{\beta}^{\text {uf }}: 0.005 ; \mathrm{TUR}^{2015}: 25 \%\right)$

$\mathrm{TUR}^{\mathrm{r}}: \underline{\beta}^{u f}: \sim 54 \%\left(\bar{\beta}^{u f}: \sim 40 \%\right)$

Total benefits: $\mathbf{2 8 1 . 8 3}$

(Gruber et al. estimates based on adoption and availability)
Total coverage cost: 209

Period: 2011-2020

$\% \Delta$ Gap to target (50\%) in 2011: $380.77 \%$

EIB

(2011)

Total coverage cost: 202

FTTH

Period: 2012-2020

Council

$\% \Delta$ Gap to target (50\%) in 2012: $354.55 \% \quad$ Europe

(2012)

Total coverage cost : $154-327$

Analysis

Period: 2011-2020

Mason

$\% \Delta$ Gap to target (50\%) in 2012: $354.55 \%$

(2013)

Total coverage cost: 213.60

Gruber

et al.

(2014)

(iii) Ultra-fast broadband gigabit society coverage target

(100 Mbit/s with $100 \%$ coverage with FTTH/B in 2025)(b)

\begin{tabular}{|c|c|c|}
\hline $\begin{array}{l}\text { Total benefits: } 252.90 \\
\left(\bar{\beta}^{u f}: 0.005 ; \mathrm{TUR}^{2015}: 25 \%\right) \\
\operatorname{TUR}^{\mathrm{r}:} \underline{\beta}^{u f}: \sim 60 \%\left(\bar{\beta}^{u f}: \sim 36 \%\right)\end{array}$ & $\begin{array}{l}\text { Total coverage cost: } 360 \\
\text { Period: } 2014-2025 \\
\% \Delta \text { Gap to target (100\%) in } 2014: 434.76 \%\end{array}$ & $\begin{array}{c}\text { BCG } \\
(2016)\end{array}$ \\
\hline
\end{tabular}




\section{Summary and conclusions}

The literature on the effects of telecommunications infrastructure investments on broader macroeconomic growth broadly found positive effects. The explanations for these positive effects range from direct effects of deployment to indirect effects due to positive externalities on the larger macroeconomy which are related to the adoption of new broadband services. These derive inter alia from potential productivity gains via more efficient business processes and more innovative products as well as easy and cheap access for citizens to services, enhancements in education skills and complementarity for entrepreneurial adoption. This literature, however, is severely constrained because it could hitherto only analyze infrastructure investment and adoption up to basic broadband but not up to the newer generations of fast and ultra-fast broadband. This is extremely important, however, since expectations of the benefits of these last generations of broadband technologies range rather high as recently expressed by the European Commission in its gigabit strategy (European Commission, 2016). This paper fills this gap and provides first EU level evidence on the incremental economic benefits of (ultra)fast broadband services.

Utilizing a comprehensive panel dataset of EU27 member states for the period from 2003-2015 and controlling for possible endogeneity of broadband adoption, we estimate a small but significant effect of ultra-fast broadband over and above the effects of basic broadband on the GDP of included countries. Fast broadband adoption is incrementally only insignificant to basic broadband. Our cost benefit analysis implies that policy intervention would only be justified for moderate coverage levels of around $50 \%$ of fast or ultra-fast broadband, whereas for $100 \%$ coverage levels we find net losses to society. Thus, it appears that - for the time being - a combination of basic broadband, fast and ultra-fast broadband entails the largest economic net benefits to society. 
One explanation would be that there is a lot of heterogeneity in consumer and business needs as well as deployment costs, and a combination of available technologies caters best to this heterogeneity. This reinforces the long-established principle of "technological neutrality" (European Commission 2009, recital 18) according to which none of feasible network scenarios should be favored a priori, instead markets should identify winning technologies. Also, we could not find clear evidence that adoption of ultra-fast broadband provides substantially higher benefits than fast broadband. Therefore, rather than choosing a specific technology in stipulated public broadband policy targets, markets provide more efficient investment decisions in a world with considerable uncertainty about future demand for high bandwidth and fast technological progress.

\section{Acknowledgements}

The authors are grateful to two anonymous referees as well as to Thomas Niebel and Frank Verboven for their helpful comments and suggestions on a former version of this paper. 


\section{Appendix}

Table A.1, Table A.2

Table A.1: Variable descriptions and sources

\begin{tabular}{|c|c|c|}
\hline Variable & Description & Source* \\
\hline \multicolumn{3}{|c|}{ Dependent variable } \\
\hline $\begin{array}{l}\text { Real GDP, } \\
G D P\end{array}$ & $\begin{array}{l}\text { Real GDP at constant } 2011 \text { national prices (in mil. } \\
\text { 2011US\$) }\end{array}$ & $\begin{array}{l}\text { Penn World } \\
\text { Table }^{(a)}\end{array}$ \\
\hline $\begin{array}{l}\text { Ultra-fast } \\
\text { broadband, } \\
B B^{u f}\end{array}$ & $\begin{array}{l}\text { Broadband variables } \\
\text { Total number of consumers subscribed to FTTH/FTTB } \\
\text { services. Subscribers can be households or business }\end{array}$ & $\begin{array}{l}\text { OFTTH Council } \\
\text { Europe }\end{array}$ \\
\hline $\begin{array}{l}\text { Fast broadband, } \\
B B^{f a}\end{array}$ & $\begin{array}{l}\text { Total number of consumers subscribed to FTTC and } \\
\text { FTTLA services. Subscribers can be households or } \\
\text { business }\end{array}$ & $\begin{array}{l}\text { FTTH Council } \\
\text { Europe }\end{array}$ \\
\hline $\begin{array}{l}\text { Basic broadband } \\
B B^{b a}\end{array}$ & $\begin{array}{l}\text { Number of total broadband internet subscribers based on } \\
\text { access equal to } 256 \mathrm{kbit} / \mathrm{s} \text {, or greater, as the sum of the } \\
\text { capacity in both directions }\end{array}$ & $\begin{array}{c}\text { EU DAE } \\
\text { Scoreboard } \\
\text { (c) }\end{array}$ \\
\hline $\begin{array}{l}\text { Capital stock, } \\
\text { capital_stock }\end{array}$ & $\begin{array}{l}\text { Capital and labour inputs } \\
\text { Capital stock at constant } 2011 \text { national prices (in mil. } \\
\text { 2011US\$) }\end{array}$ & Penn World Table \\
\hline $\begin{array}{l}\text { Total hours, } \\
\text { work_hours }\end{array}$ & Total hours worked by persons engaged & Penn World Table \\
\hline $\begin{array}{l}\text { Networked } \\
\text { Readiness Index, } \\
\text { nri }\end{array}$ & $\begin{array}{l}\text { Macroeconomic control variables } \\
\text { Propensity of a country to exploit the opportunities offered } \\
\text { by information and communications technology (ICT) }\end{array}$ & CEuromonitor $^{(\mathrm{d})}$ \\
\hline $\begin{array}{l}\text { interest rate, } \\
\text { interest rate }\end{array}$ & $\begin{array}{l}\text { Long-term interest rate for debt security issued at } 10 \text { years } \\
\text { maturity at local currency unit }\end{array}$ & $\begin{array}{c}\text { European } \\
\text { Central Bank }^{(\mathrm{e})}\end{array}$ \\
\hline $\begin{array}{l}\text { Economic freedom, } \\
\text { eco_freedom }\end{array}$ & $\begin{array}{l}\text { Economic freedom index between } 0 \text { and } 100 \text {, based on four } \\
\text { broad categories of economic freedom (Rule of Law; } \\
\text { Limited Government; Regulatory Efficiency; and Open } \\
\text { Markets) }\end{array}$ & $\begin{array}{l}\text { The Heritage } \\
\text { Foundation }^{(\mathrm{f})}\end{array}$ \\
\hline \multicolumn{3}{|c|}{ Instrumental variables (competition \& regulation) } \\
\hline $\begin{array}{l}\text { Mobile-to-fixed } \\
\text { ratio, } \\
\text { mobile_comp }\end{array}$ & $\begin{array}{l}\text { Share of the total number of mobile-cellular telephone } \\
\text { subscriptions to the total number of mobile-cellular } \\
\text { telephone subscriptions and total number of active fixed } \\
\text { landlines }\end{array}$ & $\mathrm{ITU}^{(\mathrm{g})}$ \\
\hline $\begin{array}{l}\text { Entrant's } \\
\text { market share, } \\
\text { broadband_comp }\end{array}$ & Entrant's retail market share in fixed broadband lines & $\begin{array}{l}\text { EU DAE } \\
\text { Scoreboard }\end{array}$ \\
\hline $\begin{array}{l}\text { Price for full LLU, } \\
\text { llu_price }\end{array}$ & $\begin{array}{l}\text { Monthly average total cost (=access price) for full local loop } \\
\text { unbundling (LLU) in } €\end{array}$ & $\begin{array}{l}\text { EU DAE } \\
\text { Scoreboard }\end{array}$ \\
\hline
\end{tabular}




\section{Instrumental variables (geographical)}

Ultra-fast broadb. other EU, $B B^{u f}$ eu26

Fast broadband other EU, $B B^{f a}$ e eu26

Basic broadband other EU, $B B^{b a}$ eu26
Average number of homes passed by FTTH and FTTB technologies in EU countries (other than the focal country)

Average number of homes passed by FTTC and FTTLA technologies in EU countries (other than the focal country)

Average number of fixed broadband subscriptions in all other EU26 countries (other than the focal country)
FTTH Council

Europe

FTTH Council Europe

FTTH Council Europe

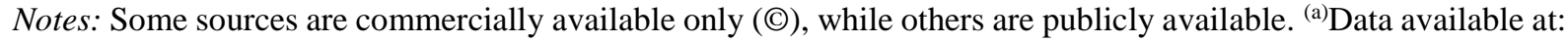
http://www.rug.nl/ggdc/productivity/pwt/ ${ }^{(b)}$ FTTH Council Europe data are available to its members at: http://www.ftthcouncil.eu/resources?category_id=6. ${ }^{(c)}$ Data available at: https://ec.europa.eu/digital-singlemarket/en/digital-scoreboard (d)Data available at: http://www.euromonitor.com/. ${ }^{(\mathrm{e})}$ Data available at: https://www.ecb.europa.eu/stats/html/index.en.html. ${ }^{(\mathrm{f})}$ Data available at: http://www.heritage.org/index/explore. ${ }^{(\mathrm{g})}$ Data available at: http://www.itu.int/ITU-D/ict/statistics/.

Table A.2: Summary statistics

\begin{tabular}{|c|c|c|c|c|c|}
\hline & count & mean & sd & $\min$ & $\max$ \\
\hline$G D P$ & 351 & 612346.5 & 863176.9 & 8402.4 & 3613889.2 \\
\hline$B B^{b a}$ & 337 & 3932314.9 & 6160487.5 & 2146 & 30104018 \\
\hline$B B^{u f}$ & 346 & 166997.0 & 348469.2 & 0 & 2587387 \\
\hline$B B^{f a}$ & 346 & 526169.0 & 1196282.5 & 0 & 9366700 \\
\hline capital_stock & 351 & 2718601.9 & 3820867.1 & 27606.0 & 13875688 \\
\hline work_hours & 351 & 13639.3 & 16252.8 & 310.8 & 58895.4 \\
\hline$n r i$ & 349 & 4.626 & 0.647 & 2.700 & 6 \\
\hline interest rate & 351 & 4.235 & 2.264 & -0.0200 & 22.50 \\
\hline eco_freedom & 351 & 68.81 & 6.057 & 50 & 82.60 \\
\hline mobile_comp & 351 & 0.736 & 0.0913 & 0 & 0.931 \\
\hline broadband_comp & 337 & 0.507 & 0.158 & 0 & 1 \\
\hline llu_price & 335 & 11.43 & 4.623 & 5.110 & 42 \\
\hline$B B^{f a} \_u 26$ & 346 & 2151314.3 & 2283850.7 & 1 & 7193497.4 \\
\hline$B B^{u f} \_$eu26 & 346 & 773391.5 & 668928.2 & 1 & 2275478.4 \\
\hline$B B^{b a}$ eu26 & 346 & 3935307.1 & 1590957.3 & 1182851.5 & 6140723.2 \\
\hline
\end{tabular}




\section{References}

Akerman, A., Gaarder, I., and Mogstad, M. (2015). The skill complementarity of broadband internet. The Quarterly Journal of Economics, 130(4), 1781-1824.

Analysis Mason (2013). The socio-economic impact of bandwidth. Study jointly carried out with tech4i2 for the European Commission.

Bacache, M., Bourreau, M. and Gaudin, G. (2014). Dynamic Entry and Investment in New Infrastructures: Empirical evidence from the Fixed Broadband Industry. Review of Industrial Organization, 44, 179-209.

Bai, Y. (2016). The Faster, the Better? The Impact of Internet Speed on Employment. Working paper available at: https://papers.ssrn.com/sol3/papers.cfm?abstract_id=2772691.

BCG - Boston Consulting Group (2016). Building the Gigabit Society: An Inclusive Path Toward Its Realization. Study carried out for ETNO.

Bertschek, I., W. Briglauer, K. Hüschelrath, B. Kauf and T. Niebel (2016). The Economic Impacts of Telecommunications Networks and Broadband Internet: A Survey. Review of Network Economics, 14, 201-227.

Bouckaert, J., Van Dijk, T., and Verboven, F. (2010). Access regulation, competition, and broadband penetration: An international study. Telecommunications Policy, 34(11), $661-671$

Bresnahan, T. F., and Trajtenberg, M. (1995). General purpose technologies 'Engines of growth'? Journal of Econometrics, 65(1), 83-108.

Briglauer, W. (2014). The Impact of Regulation and Competition on the Adoption of Fiberbased Broadband Services: Recent Evidence from the European Union Member States. Journal of Regulatory Economics, 46, 51-79.

Briglauer, W. (2015). How EU Sector-specific Regulations and Competition Affect Migration from Old to New Communications Infrastructure: Recent Evidence from EU27 Member States. Journal of Regulatory Economics, 48, 194-217. 
Cardona, M., Kretschmer, T., and Strobel, T. (2013). ICT and Productivity: Conclusions from the Empirical Literature. Information Economics and Policy, 25(3), 109-125.

Czernich, N., Falck, O., Kretschmer, T., and Woessmann, L. (2011). Broadband infrastructure and economic growth. The Economic Journal, 121(552), 505-532.

Czernich, N. (2014). Does broadband internet reduce the unemployment rate? Evidence from Germany. Information Economics and Policy, 29, 32-45.

European Commission (2009). Directive 2002/21/EC on a common regulatory framework for electronic communications networks and services (Framework Directive) as amended by Directive 2009/140/EC and Regulation 544/2009, Brussels.

European Commission (2010). A Digital Agenda for Europe. Brussels. Available at: https://www.kowi.de/Portaldata/2/Resources/fp/2010-com-digital-agenda.pdf.

European Commission (2016a). Proposal for a Directive of the European Parliament and of the Council establishing the European Electronic Communications Code (Recast). COM/2016/0590 final - 2016/0288 (COD), Brussels.

European Commission (2016b). Connectivity for a Competitive Digital Single Market Towards a European Gigabit Society. COM(2016)587 final, Brussels.

European Commission (2016c). Europe's Digital Progress Report 2016. Brussels. Available at: https://ec.europa.eu/digital-single-market/en/download-scoreboard-reports.

European Commission (2016d). Report on Implementation of the EU regulatory framework for electronic communications. Brussels.

EIB - European Investment Bank (2011). The Economic impact of fixed and mobile high-speed networks. EIB papers, 16(2), 30-60.

Fabling, R., and Grimes, A. (2016). Picking up speed: Does ultrafast broadband increase firm productivity? Motu working paper, 16-22. 
FTTH Council Europe (2012). The Cost of Meeting Europe's Network Needs. Ventura Partners study available at: http://www.ftthcouncil.eu/documents/Reports/2012/Cost_Model_Report_Full_Version.pdf.

Grajek, M. and L.-H. Röller (2012). Regulation and investment in network industries: evidence from European telecoms. Journal of Law and Economics, 55(1), 189-216.

Greenstein, S. and R. McDevitt (2011). The Broadband Bonus: Estimating Broadband Internet's Economic Value. Telecommunications Policy, 35, 617-632.

Gruber, H., J. Hätönen and P. Koutroumpis (2014). Broadband Access in the EU: An Assessment of Future Economic Benefits. Telecommunications Policy, 38, 1046-1058.

ITU/UNESCO (2010). Broadband: A platform for progress, A Report by the Broadband Commission for Digital Developement. Available at: http://www.broadbandcommission.org/Documents/publications/Report_2.pdf.

Koutroumpis, P. (2009). The economic impact of broadband on growth: A simultaneous approach. Telecommunications Policy, 33(9), 471-485.

Nardotto, M., Valletti, T. and F. Verboven (2015). Unbundling the Incumbent: Evidence from UK Broadband. Journal of the European Economic Association, 13(2), 330-362.

Röller, L. H., and Waverman, L. (2001). Telecommunications infrastructure and economic development: A simultaneous approach. American Economic Review, 91(4), 909-923.

Sosa, D. (2014). Early Evidence Suggests Gigabit Broadband Drives GDP. Analysis Group. Available at: http://www.analysisgroup.com/uploadedfiles/content/insights/publishing/gigabit_broadband_sosa.pdf. 